\title{
Reassessing the Plastic Hinge Model for Energy Dissipation of Axially Loaded Columns
}

\author{
R. M. Korol and K. S. Sivakumaran \\ Department of Civil Engineering, McMaster University, Hamilton, ON, Canada L8S 4L7 \\ Correspondence should be addressed to K. S. Sivakumaran; siva@mcmaster.ca
}

Received 30 October 2013; Accepted 30 December 2013; Published 13 February 2014

Academic Editor: Mustafa Kemal Apalak

Copyright (c) 2014 R. M. Korol and K. S. Sivakumaran. This is an open access article distributed under the Creative Commons Attribution License, which permits unrestricted use, distribution, and reproduction in any medium, provided the original work is properly cited.

\begin{abstract}
This paper investigates the energy dissipation potential of axially loaded columns and evaluates the use of a plastic hinge model for analysis of hi-rise building column collapse under extreme loading conditions. The experimental program considered seven axially loaded $\mathrm{H}$-shaped extruded aluminum structural section columns having slenderness ratios that would be typical of floor-to-ceiling heights in buildings. All seven test specimens initially experienced minor-axis overall buckling followed by formation of a plastic hinge at the mid-height region, leading to local buckling of the flanges on the compression side of the plastic hinge, and eventual folding of the compression flanges. The experimental energy absorption, based on load-displacement relations, was compared to the energy estimates based on section plastic moment resistance based on measured yield stress and based on measured hinge rotations. It was found that the theoretical plastic hinge model underestimates a column's actual ability to absorb energy by a factor in the range of 3 to 4 below that obtained from tests. It was also noted that the realizable hinge rotation is less than $180^{\circ}$. The above observations are based, of course, on actual columns being able to sustain high tensile strains at hinge locations without fracturing.
\end{abstract}

\section{Introduction}

Ever since the collapse of the 110 storey twin towers in New York, USA, the research efforts have intensified on the topics such as progressive collapse of buildings [1,2], blast resistant design of buildings $[3,4]$ and energy dissipation of structures $[5,6]$. Some studies exist on the topic of energy dissipation of structural members, however, they are generally confined to the automotive industry whose aim is to improve crash worthiness of their manufactured vehicles. Information of an equivalent nature appears to be lacking for structural engineers concerned with the integrity of building columns that are required to resist the consequences of blast loads or very hot fires, with the objective being to prevent a catastrophic global collapse.

Bazant and Zhou [7] published a paper titled "Why Did the World Trade Center Collapse? Simple Analysis" providing the engineering community with insights into why those steel structures collapsed. In their simple analysis it was assumed that the columns failed due to folding at the localized plastic hinges. This type of model is commonly employed for laterally loaded beams and girders, that is, assume that these structural members form plastic hinges at mid height during the motion of one storey closing the gap distance with its neighboring storey by bending into a closed scissors state. Bazant and Zhou [7] postulated that at least one plastic hinge and no more than three plastic hinges, per column line are needed to operate simultaneously in order to allow the upper part to continue moving down. It was argued that at the end, the sum of the rotation angles of the hinges on one column line cannot exceed $360^{\circ}$, and therefore, the most optimistic plastic energy dissipation in a column was taken as the plastic bending moment $\mathrm{Mp}$ of one column times the combined rotation angle of $2 \pi$ radian. In one sense, it might be argued that such a hypothesis would overestimate the energy absorbing capacity, since the possibility of fracture in tension zones of the plastic hinge is excluded. On the other hand, the plastic hinge assumption might underestimate the capacity by virtue of disregarding the axial energy capacity and ignoring the slenderness parameter that is key to column design. An earlier study on square hollow shaped columns clearly shows that employing the plastic hinge analysis method very 


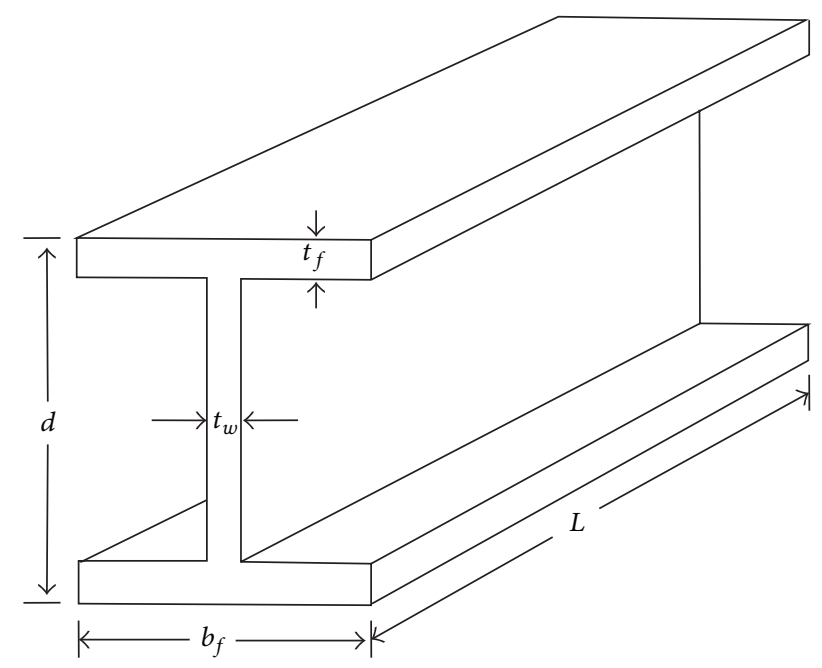

Figure 1: Cross section of $\mathrm{H}$-shaped test specimens.

much underestimates the energy absorbing capacity during a squash type mechanism of collapse [8]. This investigation intends to explore whether $\mathrm{H}$-shaped structural columns absorb more or less energy than predicted by the plastic hinge model [7]. This paper presents experimentally established energy dissipations associated with axially loaded $\mathrm{H}$-shaped columns of intermediate slenderness and compares them to those established based on a plastic hinge model.

\section{The Experimental Program}

The experimental program consisted of seven axially loaded columns, all of which were cut from an H-shaped extruded aluminum structural section having a nominal depth of $76.2 \mathrm{~mm}\left(3^{\prime \prime}\right)$ and a width of $63.5 \mathrm{~mm}\left(2.5^{\prime \prime}\right)$. Figure 1 shows the cross section of the shape used in our tests, in which $d=$ $76.2 \mathrm{~mm}\left(3^{\prime \prime}\right), t_{w}=4.76 \mathrm{~mm}\left(3 / 16^{\prime \prime}\right), b_{f}=63.5 \mathrm{~mm}\left(2.5^{\prime \prime}\right)$, and $t_{f}=6.35 \mathrm{~mm}\left(1 / 4^{\prime \prime}\right)$. These are nominal dimensions of the section and were confirmed by taking measurements at several random cross-section locations. Excluding the corner fillets, the resulting section properties are area $=1109 \mathrm{~mm}^{2}$, major axis second moment of area $=1088 \times 10^{3} \mathrm{~mm}^{4}$, minor axis second moment of area $=271.6 \times 10^{3} \mathrm{~mm}^{4}$, major axis radius of gyration $=31.3 \mathrm{~mm}$, and the minor axis radius of gyration $=15.6 \mathrm{~mm}$. Since these tests were intended to simulate building columns, the lengths were chosen so as to achieve effective slenderness ratios that would be typical of floor-to-ceiling heights in buildings, ranging from 33 to 42 .

Column 1 of Table 1 shows specimen identification. Symbols used to denote individual specimens were prefixed by "SR" to denote slenderness ratio, while the number following indicates the $(L / r)$ ratio about the minor axis, where $L$ is the length of the column and $r$ is the corresponding radius of gyration. The letters (a) and (b) denote duplicate tests undertaken for the same slenderness indicated. As shown in Column 2 of Table 1, the resulting specimen lengths ranged from $511 \mathrm{~mm}$ to $660 \mathrm{~mm}$. The test specimen material is aluminum alloy 6061-O (major alloying ingredients being

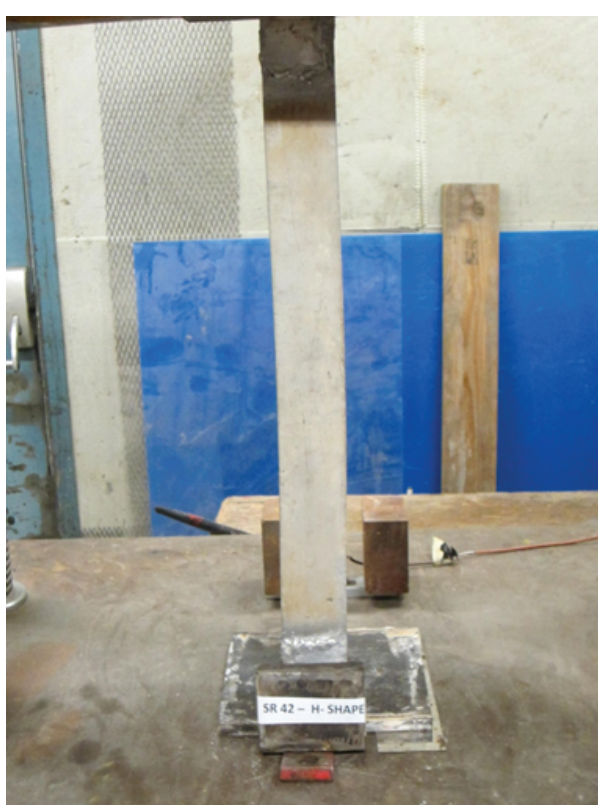

FIgURE 2: Compression test specimen SR 42 prior to loading.

magnesium and silicon-annealed temper). This alloy allows for a maximum amount of deformation before fracturing (improved ductility and dimensional stability), thus providing a basis for comparing responses with mild steel. Another reason for such a selection is that this grade has lower yield and ultimate strength values than does the conventional T6 tempered aluminum which is a benefit for cases where testing machines have limited loading capacities. The mechanical properties of the aluminum alloy were measured through tension coupon tests and found to have a yield stress (based on a $0.2 \%$ offset strain) of $58 \mathrm{MPa}$ and a tensile strength of $129 \mathrm{MPa}$.

All specimens were prepared with ends cut square to ensure even contact with the testing machine platens. However, in order to avoid localized crimping of flanges during loading, small aluminum angles were welded to the flanges. So as to prescribe simply-supported end conditions, the specimens were not restrained by the machine's base plate and upper platen, thus allowing the specimen ends to freely rotate during the course of buckling. McMaster University's Applied Dynamics Laboratory Riehle testing machine with a capacity of $2000 \mathrm{kN}$ was employed for this experimental program. A typical test setup is shown in Figure 2. Though it may not be clear from this figure, two string-type LVDTs were employed on opposite sides of a specimen, attached to the top and bottom platens, to measure axial displacements of the specimens. The specimens were aligned and centered with respect to the testing machine prior to application of loads.

A slow loading rate was applied to a given specimen (2 or $3 \mathrm{~mm} /$ minute) until the peak load was reached, after which it was increased gradually to a maximum of $10 \mathrm{~mm} /$ minute by the end of a test. The test continued well past the peak loads. All seven test specimens initially experienced minoraxis overall buckling followed by formation of a plastic hinge at the mid-height region. Figure 3 shows photographs of 


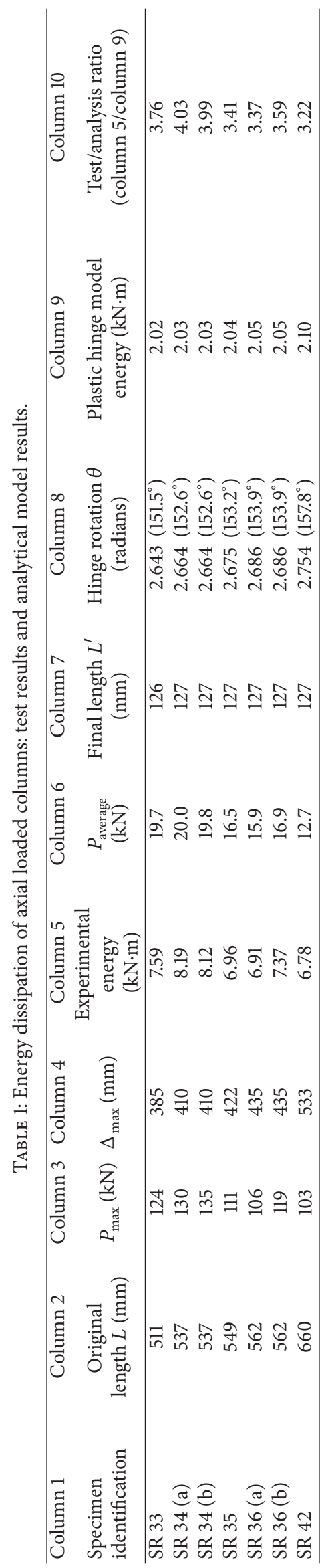



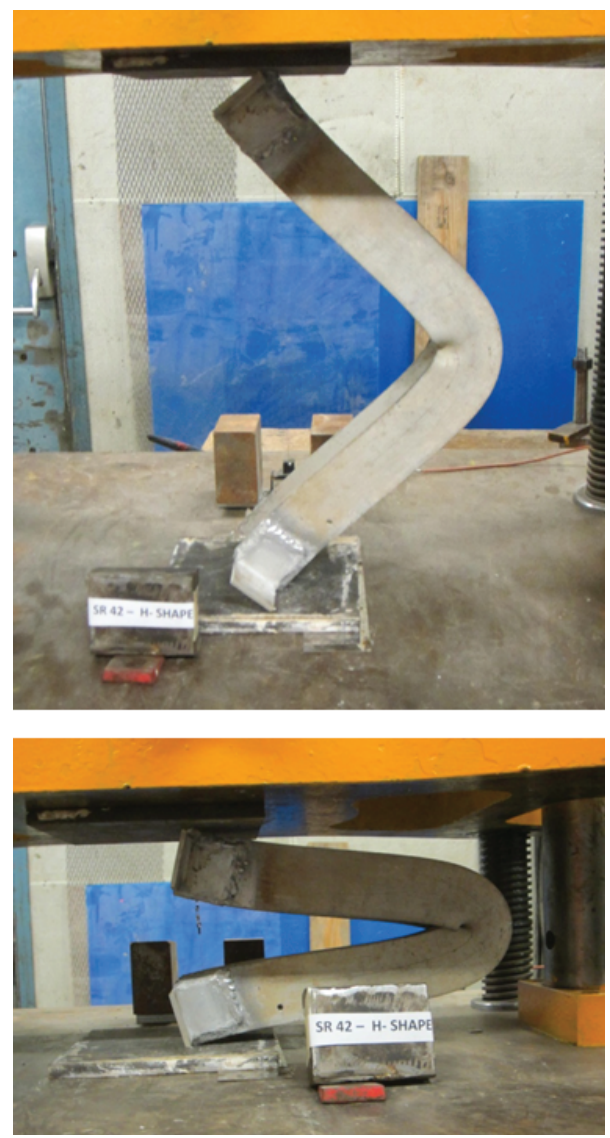

Figure 3: Photographs of SR 42 specimen loaded well into the postmaximum range.

specimen SR 42 in the testing machine in postmaximum load conditions. Continued loading led to local buckling of the flanges on the compression side of the plastic hinge. Figure 4 shows the folds that form on the compression side of the plastic hinge associated with specimen SR 35. All seven test specimens exhibited this compression flange local buckling followed by folding. Such contact of the insides of the flanges was noted for all specimens and is shown in Figure 5 which was assembled after completion of the experimental program. In each test the experiment was terminated once it was evident that flanges above and below the hinge were in contact with one another. Had we continued the test beyond contact of the flanges, the residual resistance would continue even with such severe folding, since another fold above or below the original can occur, as noted in crush tests on square hollow sections [8]. Continued testing might have even shown a rise of load resistance with augmented energy absorption. However, attempting to include such a clash of flange-on-flange was deemed to be beyond the scope of reassessing the plastic hinge model for energy dissipation of axially loaded columns.

Experimental Results of H-Shapes Subject to Axial Loading. Figure 6 shows the load-displacement plots from the computer data generated during testing of all seven specimens. For example, the specimen SR33, which had an original

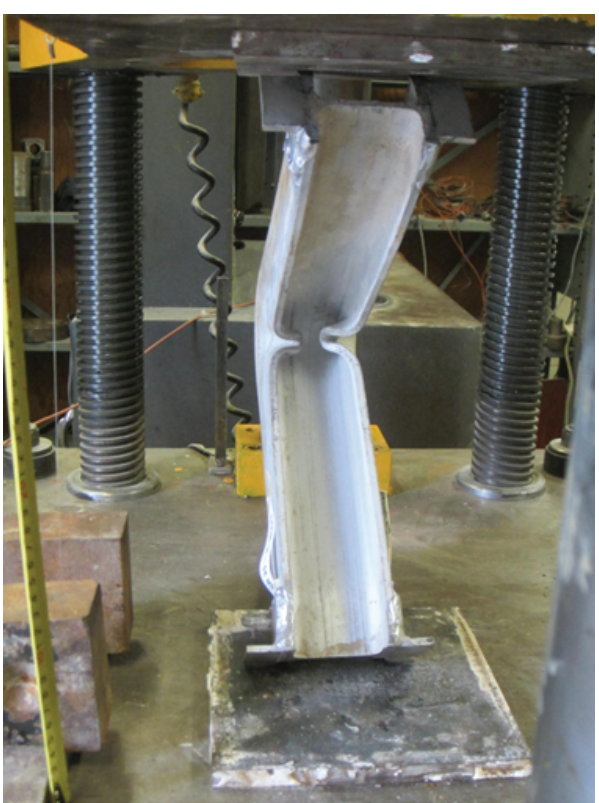

FIGURE 4: Compression flange folds of SR 35 in a state of large displacement.

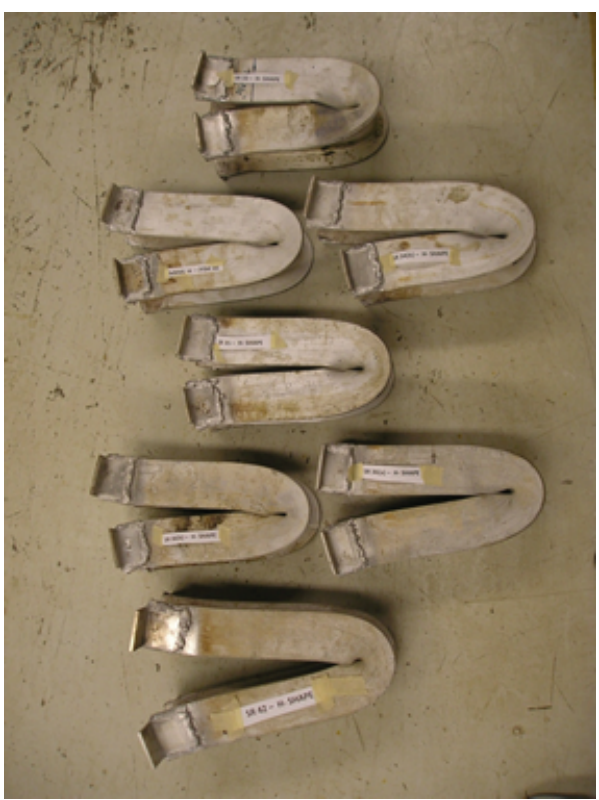

FIGURE 5: Specimens after test completion.

length of $511 \mathrm{~mm}$, reached a maximum load of $124 \mathrm{kN}$, which occurred at an axial displacement of $15.1 \mathrm{~mm}$. This was followed by flange buckling at mid-height and a consequent severe drop-off in load resistance as the upper cross head movement progressed. It is evident that there is a precipitous loss of strength by about an order of magnitude compared with the maximum strength values noted in the diagrams in Figure 6 and in Table 1. For large $b_{f} / t_{f}$ ratios this result is to be expected since it is well known that axially compressed unsupported flanges buckle elastically at much lower stresses than do those that have connecting 

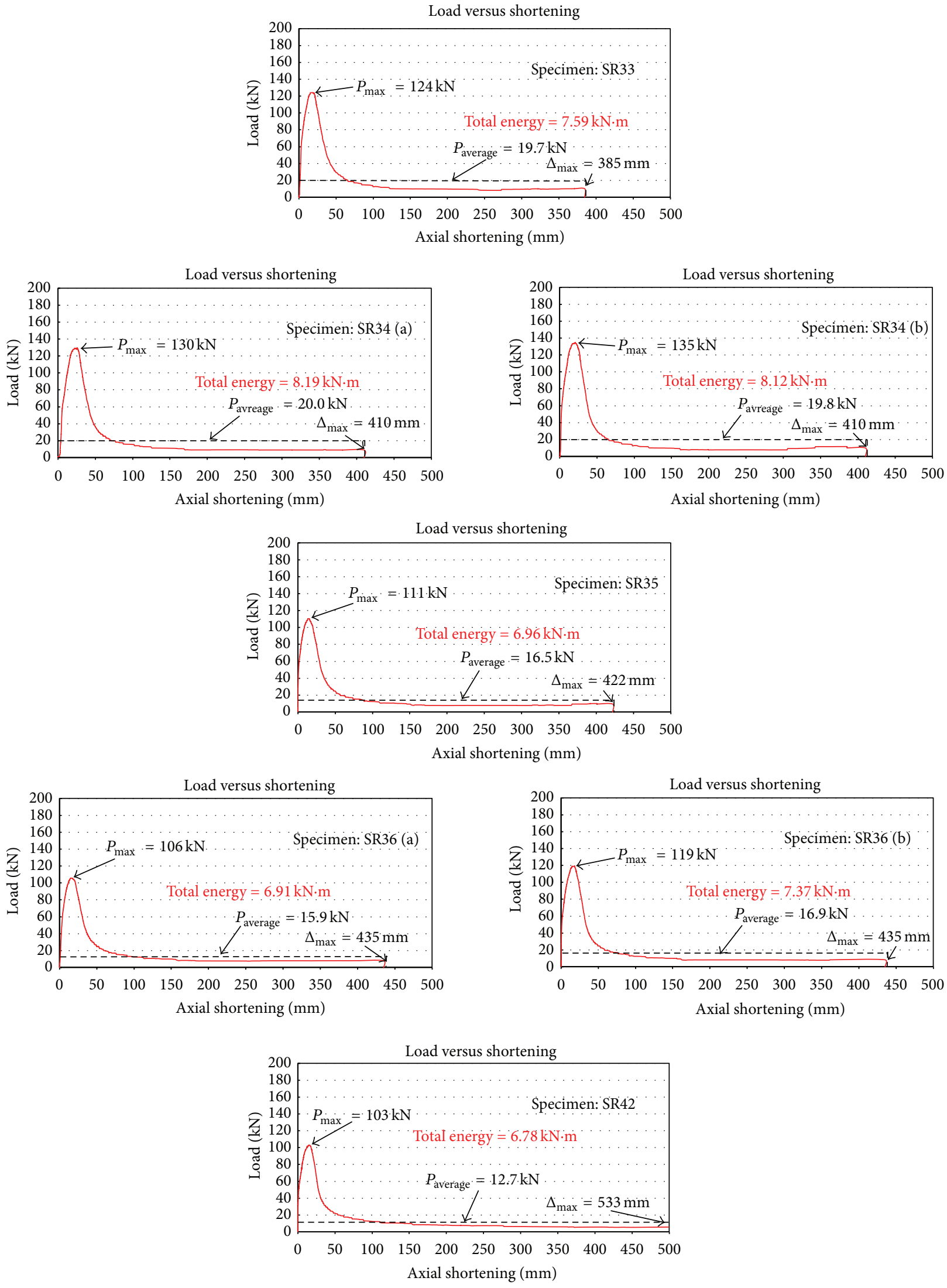

Figure 6: Axial load-displacement plots of specimens noted. 


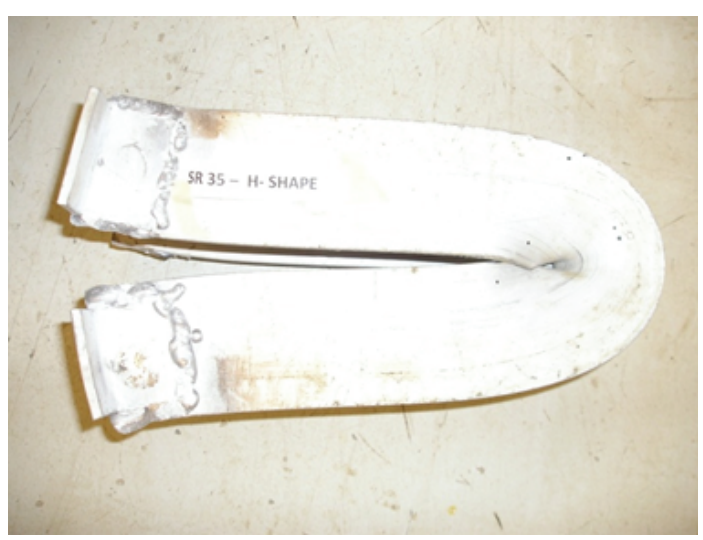

(a)

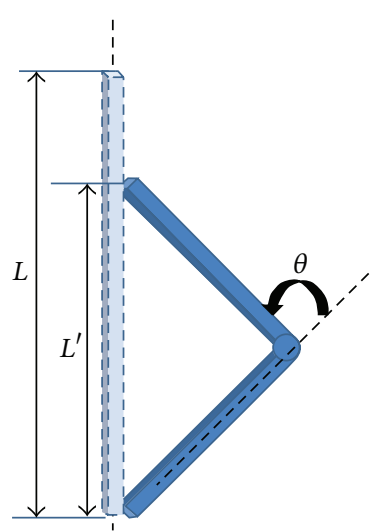

(b)

FigurE 7: Experimental and idealized plastic-hinged column at maximum displacement.

elements [9], a reference which simply validates the work of many outstanding researchers over recent decades. But even in the inelastic response range, the importance of the buckling plate coefficient with respect to boundary conditions for classification of sections into design categories is dependent on both geometrical and material properties [10].

The establishment of the amount of energy associated with converting a straight column into one that has a kink at mid-height requires knowledge of its load-displacement relationship. This was achieved via instrumentation described earlier linking the loads to averaged LVDT readings of crosshead displacements. The columns 3 and 4 given in Table 1 show the peak loads and the peak displacements, respectively, observed in each test. The energy absorbed during an entire displacement range is, of course, the area under the curve and is summarized in Column 5 of Table 1. Note that the energy dissipated by the axially loaded columns ranged from a high energy of $8.19 \mathrm{kN} \cdot \mathrm{m}$ to a low energy of $6.78 \mathrm{kN} \cdot \mathrm{m}$. The other pertinent information noted in Figure 6 is the average load resistances exhibited by the columns tested, which have been summarized in Column 6 of Table 1 . Data from the seven plots, and as summarized in the Table 1, suggests that as the slenderness ratio increases, the average load of resistance decreases, that is, reducing from $20 \mathrm{kN}$ (SR 33) to $12.7 \mathrm{kN}$ (SR 42). Of course, definitive conclusions cannot be made in this regard, but it does suggest that postbuckling resistance would decrease as a given column section increases in length, inferring the importance of slenderness ratio in assessing the energy dissipation potential for columns subjected to displacements of the order of their lengths.

The final lengths of the test specimens were derived based on the original lengths and the peak axial displacements and are given in Column 7-Table 1. For example, specimen SR35 which had an original length of $549 \mathrm{~mm}$ was axially loaded for a maximum displacement of $422 \mathrm{~mm}$, resulting in a final length of specimen of $127 \mathrm{~mm}$. In this case the crush test was conducted until the displacement into a scissors-shaped configuration of the column reached approximately $77 \%$ of the original height (422/549). Figure 7 shows specimen SR35 after test. The plastic hinge rotation associated with such a displacement can be estimated from the formula $\theta=$ $\pi-2 \sin ^{-1}\left(L^{\prime} / L\right)$, where $\theta$ is the angle through which the two segments are rotated, which represents the localized rotation at mid-height associated with $\Delta_{\max }$ (see Figure 7). The plastic hinge rotations for all seven specimens were calculated and are tabulated in Column 8 of Table 1 . Note that the rotations are expressed in radians and the corresponding angles are given within brackets. As shown in Column 8 of Table 1 , the experimental hinge rotations, that is, the scissors angle just at the point of flange clashing, are in the range of $150-160^{\circ}$.

\section{Discussion and Conclusions}

The energy dissipated in a plastic hinge undergoing a plastic rotation $\theta$ is given as $M_{p} \theta$, where $M_{p}$ is plastic moment resistance based on the assumption that the cross-section will indeed reach the plastic moment prior to flange local buckling. Since bending in these experiments is about the minor axis, we need to compute the corresponding plastic section modulus, $Z_{p}$, for the section shown in Figure 1. For an idealized $\mathrm{H}$-shape that neglects the corner radius effects, the minor-axis plastic section modulus, computed using the expression $Z_{p}=1 / 4\left[b_{f}^{2} \cdot 2 t_{f}+t_{w}^{2} \cdot\left(d-2 t_{f}\right)\right]$, is $13,162 \mathrm{~mm}^{3}$. Since the yield stress based on a $0.2 \%$ offset was determined to be $58 \mathrm{MPa}$, we compute the fully plastic moment about the minor axis to be $0.763 \mathrm{kN} \cdot \mathrm{m}$. We then determine the energy dissipation for the plastic hinge by multiplying by $\theta$ for each of our tests. The plastic hinge model-based energy results are given in Column 9 of Table 1. Column 10 of Table 1 compares the experimental energy values with the corresponding energy values based on the hinge model. It is evident that regardless of the slenderness ratio, the ratio of experimental amount of energy absorbed by an $\mathrm{H}$-column under pure axial compression is three to four times greater than what the plastic hinge model analysis predicts.

It must be acknowledged that the plastic hinge model calculations employed a yield stress value of $58 \mathrm{MPa}$, which 
is well below the tensile strength of the material of $129 \mathrm{MPa}$. Under large hinge rotations, such as the scenario associated with these experiments, the strains at the hinge location might have been very high and thus stress approaching tensile strength of the material. Had the tensile strength been used in the energy calculations based on plastic hinge model, the ratio of experimental energy absorbed by an $\mathrm{H}$ column under pure axial compression is on average 1.63 times greater than what the plastic hinge model analysis based on tensile strength predicts. While the yield/tensile ratio of material used $(58 / 129=0.45)$ may appear to be low to serve as a comparison with steel building columns, the yield-totensile ratio of grade A36 steel, a common grade of steel for structural shapes, ranges between 0.45 and 0.62 [11].

While our test program was very limited in the both the number and types of experiments undertaken, our findings suggest that the energy dissipation of axially loaded columns depends on various parameters, namely, slenderness of the column, tensile strength and the ductility of the material, and so forth, and its estimation is not a trivial matter. While the plastic hinge model does have merit in its simplicity and may be better suited for analysis of laterally loaded members, its application to axially loaded columns warrants caution. There clearly are limitations to applying such a model when dealing with structural members that primarily resist axial loads. Overall, there is a need by the structural engineering community to further investigate the issue of energy dissipation potentials of steel columns and their role in mitigating progressive collapse of buildings.

\section{Conflict of Interests}

The authors declare that there is no conflict of interests regarding the publication of this paper.

\section{References}

[1] B. R. Ellingwood, R. Robert Smilowitz, D. O. Dusenberry, D. Duthinh, H. S. Lew, and N. J. Carino, "Best practices for reducing the potential for progressive collapse in buildings," Internal Report NISTIR 7396, The National Institute of Standards and Technology Interagency, Gaithersburg, Md, USA, 2007.

[2] A. G. Vlassis, B. A. Izzuddin, A. Y. Elghazouli, and D. A. Nethercot, "Progressive collapse of multi-storey buildings due to failed floor impact," Engineering Structures, vol. 31, no. 7, pp. 1522-1534, 2009

[3] M. Gündel, B. Hoffmeister, M. Feldmann, and B. Hauke, "Design of high rise steel buildings against terrorist attacks," Computer-Aided Civil and Infrastructure Engineering, vol. 27, no. 5, pp. 369-383, 2012.

[4] A. A. Nassr, A. G. Razaqpur, M. T. Tait, M. Campidelli, and S. Foo, "Strength and stability of steel beam columns under blast load," International Journal of Impact Engineering, vol. 55, pp. 34-48, 2013.

[5] F. Tarlochan, S. Ramesh, and S. Harpreet, "Advanced composite sandwich structure design for energy absorption applications: blast protection and crashworthiness," Composites B, vol. 43, no. 5, pp. 2198-2208, 2012.
[6] R. M. Korol and K. S. Sivakumaran, "Energy absorption potential of light weight concrete floors," Canadian Journal of Civil Engineering, vol. 39, pp. 1193-1201, 2012.

[7] Z. Bazant and Y. Zhou, "Why did the World Trade Center collapse?-simple analysis," Journal of Engineering Mechanics, vol. 128, no. 1, pp. 2-6, 2002, Addendum to Journal of Engineering Mechanics, vol. 128, no. 3, pp. 369-370, 2002.

[8] R. M. Korol and K. S. Sivakumaran, "Energy dissipation potential of square tubular steel columns subjected to axial compression," International Review of Civil Engineering, vol. 2, no. 1, pp. 46-51, 2011.

[9] SSRC, Guide to Stability Design Criteria for Metal Structures, chapter 4, SSRC, Rolla, Mo, USA, 5th edition, 2009.

[10] CISC, Handbook of Steel Construction, Willowdale, Ontario, Canada, 9th edition, 2006.

[11] T. V. Galambos, F. J. Lin, and B. G. Johnston, Basic Steel Design with LRFD, Prantice-Hall, Upper Saddle River, NJ, USA, 1996. 

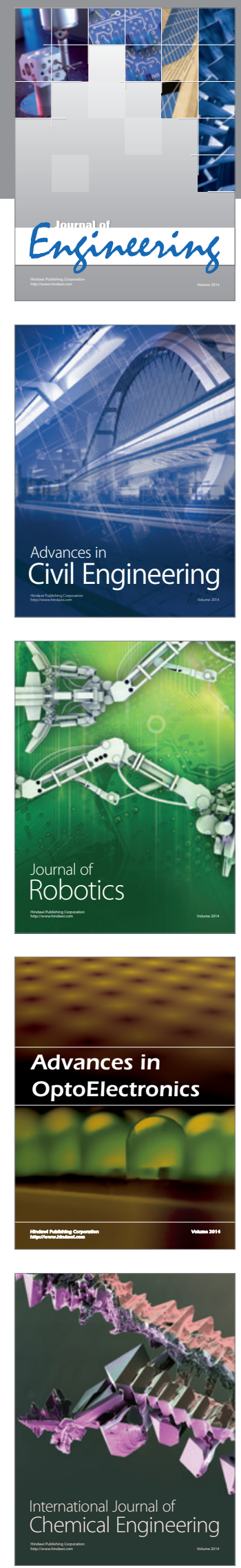

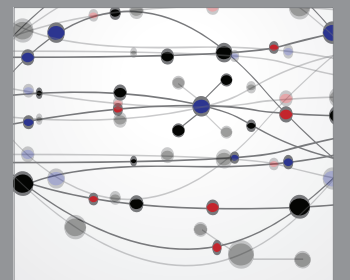

The Scientific World Journal
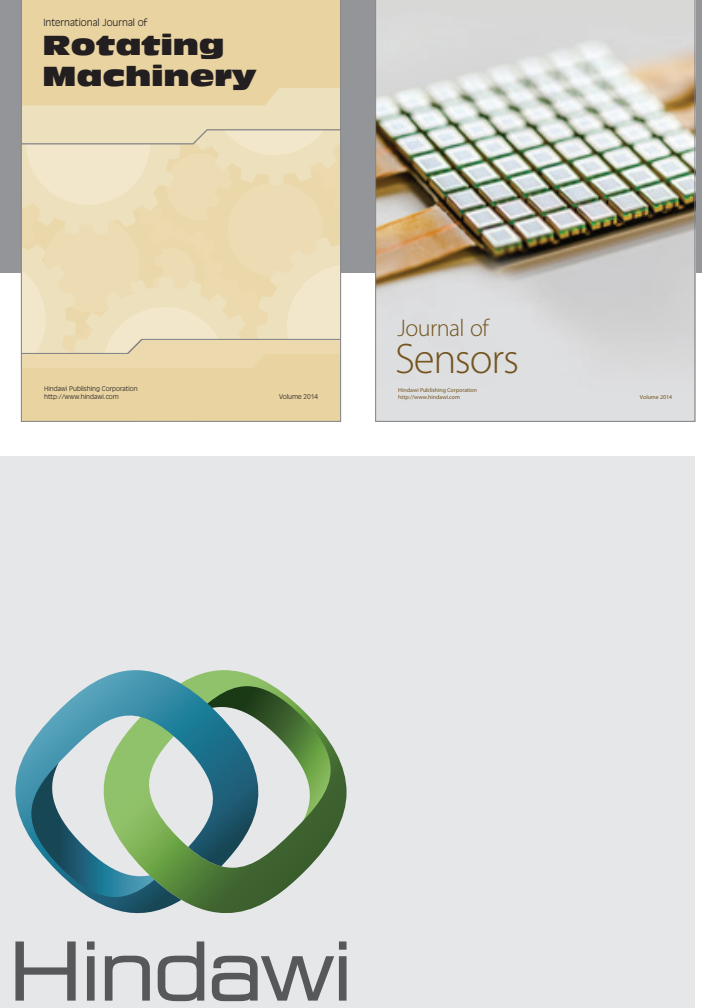

Submit your manuscripts at http://www.hindawi.com
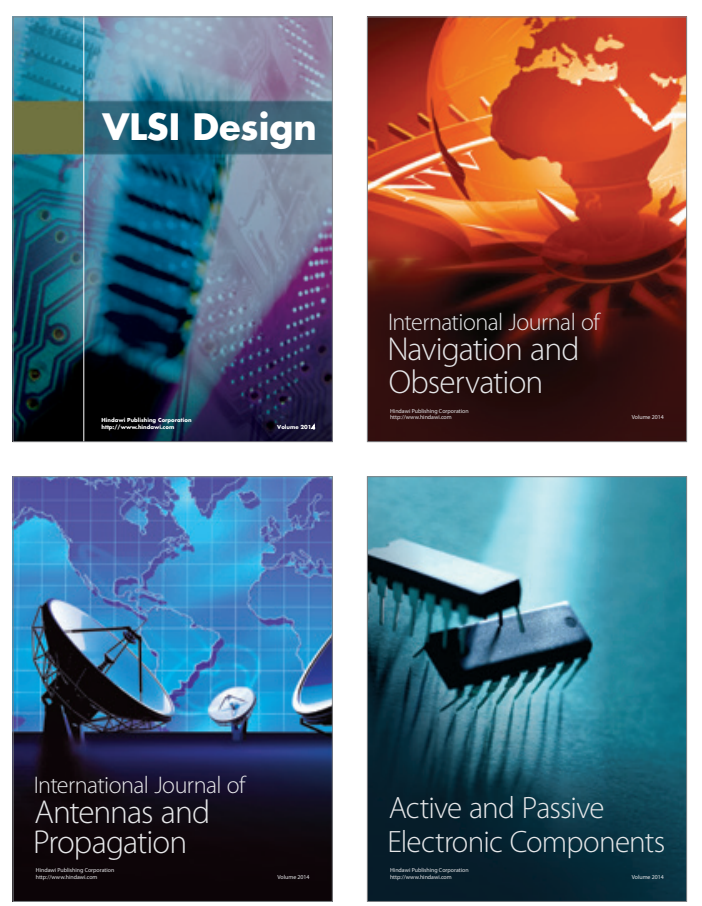
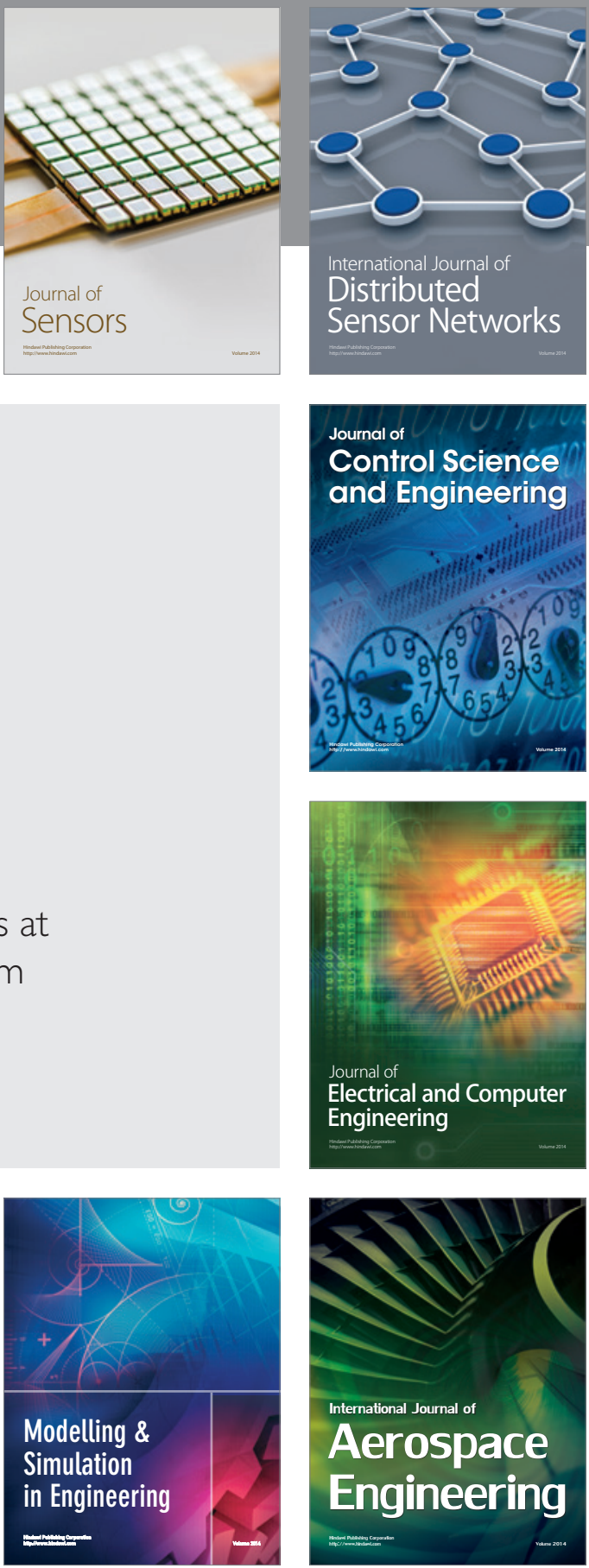

Journal of

Control Science

and Engineering
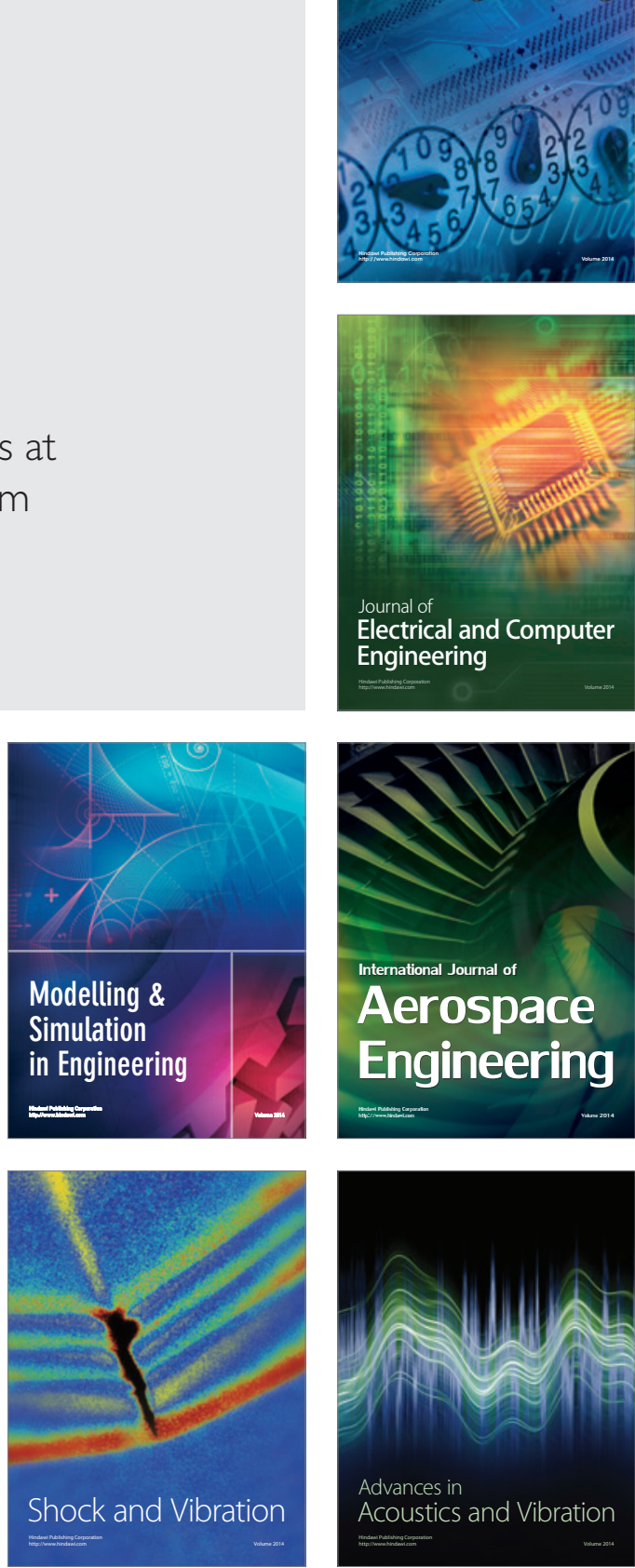